\title{
O ENSINO DE HISTÓRIA DA ÁFRICA NA FORMAÇÃO CONTINUADA DE PROFESSORES: DESAFIOS E PERSPECTIVAS PARA A EDUCAÇÃO
}

\author{
Carolina Corbellini Rovaris \\ Universidade do Estado de Santa Catarina \\ carolcrovaris@gmail.com
}

\begin{abstract}
Resumo
O presente artigo visa contribuir para a discussão acerca do ensino de História da África na educação básica, apontando alguns desafios e perspectivas colocados por professores nos fóruns de discussão do Curso de Formação Continuada à distância intitulado "Introdução aos Estudos Africanos e da Diáspora", organizado pelo Núcleo de Estudos AfroBrasileiros (NEAB) da Universidade do Estado de Santa Catarina (UDESC). O curso apresentava como objetivo geral formar professores (as) da rede de ensino público e privada, na temática da História da África e das populações de origem africana na Diáspora. Tal ação visava contribuir para a implementação dos princípios e dos fundamentos contidos nas Diretrizes Curriculares Nacionais para a Educação das Relações Étnico-Raciais e para o Ensino de História e Cultura AfroBrasileira e Africana.

Palavras-chave: África. Educação. História. Professores.
\end{abstract}

\section{THE TEACHING HISTORY OF AFRICA IN CONTINUING EDUCATION: CHALLENGES AND PERSPECTIVES FOR THE EDUCATION}

Abstract

This article aims to contribute to the discussion about the teaching of Africa's History in the basic education, pointing out some challenges and perspectives presented by teachers in the discussion forums of the distance Course Continuing Education entitled "Introduction to African and Diaspora Studies", organized by the Núcleo de Estudos Afro-Brasileiros (NEAB) of the Universidade do Estado de Santa Catarina (UDESC). The course presented as its general objective train teachers of public and private schools in the theme about History of Africa and of the African descendants in the Diaspora. This action aims to contribute to the implementation of the principles and provisions set forth in the National Curriculum Guidelines for the Education of Racial-Ethnic Relations and the Teaching of Afro-Brazilian and Africa's History.

Keywords: Africa. Education. History. Teachers.

\section{LA ENSEÑANZA DE HISTORIA DE ÁFRICA EN LA EDUCACIÓN CONTINUADA DE LOS MAESTROS: DESAFÍOS Y PERSPECTIVAS PARA LA EDUCACIÓN}

\section{Resumen}

En este artículo se pretende contribuir a la discusión sobre la enseñanza de la Historia de África en la educación básica, señalando algunos desafíos y perspectivas que plantean los profesores en los foros de discusión del curso de Educación Continuada a Distancia titulado " Introducción a los Estudios Africanos y de la Diáspora", organizado por el Núcleo de Estudos Afro-Brasileiros (NEAB), de la Universidade do Estado de Santa Catarina (UDESC). El curso tuvo como objetivo principal capacitar a los maestros(as) del sistema escolar público y privado, el tema de la Historia de África y las poblaciones de ascendencia africana en la diáspora. Esta acción estaba destinada a contribuir a la aplicación de los principios y disposiciones establecidos en las Directrices Curriculares Nacionales para la Educación de las relaciones étnico-racial y la enseñanza de la cultura afro-brasileña y africana.

Palabras clave: África. Educación. Historia. Maestros. 


\section{O CURSO INTRODUÇÃO AOS ESTUDOS AFRICANOS E DA DIÁSPORA: UMA AÇÃO DE EXTENSÃO}

O projeto de extensão "História da África e das Populações de Origem Africana na Diáspora”, organizado pela professora Doutora Claudia Mortari, do Núcleo de Estudos AfroBrasileiros (NEAB) da Universidade do Estado de Santa Catarina (UDESC) tinha como propósito contribuir para a implementação da Lei Federal n. ${ }^{\circ}$ 10.639/2003 e das Diretrizes Curriculares Nacionais para a Educação das Relações Étnico-Raciais e para o Ensino de História e Cultura Afro-Brasileira e Africana (Resolução no 1, de 17 de junho de 2004). Neste sentido, foi desenvolvido e implementado um Curso de Formação Continuada de professores à distância intitulado "Introdução aos Estudos Africanos e da Diáspora". O curso tinha como objetivos disseminar conhecimentos, periodizar, definir e problematizar alguns temas e conceitos referentes à História das Áfricas e das experiências empreendidas pelas populações de origem africana na diáspora, visando romper com visões simplificadoras acerca dos processos históricos, além de estimular discussões que contribuíssem para o questionamento das tradições eurocêntricas presentes nos currículos escolares, através da capacitação de professores da rede pública e privada de ensino da temática.

Por ser um curso a distância, contamos com o apoio do Centro de Educação a Distância CEAD, que disponibilizou e auxiliou ao uso da Plataforma Moodle, usada como ferramenta para o desenvolvimento do trabalho. Na Plataforma foram abertas dez salas virtuais, contendo 50 cursistas em cada. O curso foi realizado no período de 03 de abril a 21 de junho de 2013.

Tal ação, ao disseminar conhecimentos relativos à temática, proporcionou a apropriação de referenciais históricos para a reflexão do tema e incorporação nos currículos e nas práticas pedagógicas de conteúdos e de ações que possibilitem à comunidade escolar estabelecer uma reflexão sobre a diversidade, que exercite e lute pelo direito de cidadania, de solidariedade e de respeito para com todas as referências culturais de africanos e seus descendentes na sociedade atual, construindo possibilidades para o enfrentamento da discriminação.

Sendo assim, este artigo tem como objetivo analisar as discussões que ocorreram em dois fóruns do curso, visando compreender que desafios e perspectivas foram colocados pelos professores ao se pensar o ensino de história da África na educação básica.

\footnotetext{
${ }^{1}$ Este curso já estava na sua terceira edição, no ano de 2013. A primeira edição do curso ocorreu em 2011, também como uma ação do projeto de extensão História da África e das Populações de Origem Africana na Diáspora. Tal projeto fez parte de dois Programas de Extensão: Diversidade Étnica na educação (Edital UDESC/PAEX de 2012) e Memorial Antonieta de Barros (Edital MEC/PROEXT 2011).
} 
O ensino de história da África na formação continuada de professores: desafios e perspectivas para a educação

\section{A ESTRUTURA DO CURSO}

Os conteúdos trabalhados no curso "Introdução aos Estudos Africanos e da Diáspora" foram organizados em três módulos, disponibilizados através da Plataforma Moodle. No módulo I intitulado "O Ensino de História da(s) África(s): alguns apontamentos”, o conteúdo foi dividido em dois capítulos. Neles está presente uma discussão acerca do ensino de História da África, da historiografia africana e africanista, finalizando com uma abordagem sobre a concepção de tempo, história, ancestralidade e mito para algumas sociedades africanas. No módulo II, "História da África (séculos XV ao XIX)", também contendo dois capítulos, a abordagem é focada em algumas sociedades, suas formas de organização, suas diversidades e complexidades e o contato com os europeus, com destaque para as da região ocidental, central e oriental do continente. No módulo III, "Experiências das populações africanas e afrodescendentes na diáspora", os conteúdos foram organizados em quatro capítulos, nos quais se aborda a temática da diáspora africana ocorrida através do tráfico atlântico, dos vínculos familiares, das irmandades religiosas, das lutas por emancipação no pós-abolição e da constituição do movimento negro no Brasil, objetivando dar visibilidade às múltiplas experiências, aos modos de vida, aos arranjos sociais e à luta por parte destas populações para sobreviver, lutar por liberdade e transformar suas vidas.

Este material foi produzido por professores e professoras, pesquisadores e alunos e alunas do curso de História do Centro de Ciências Humanas e da Educação (FAED), da Universidade do Estado de Santa Catarina (UDESC), todos vinculados, de alguma maneira, ao Núcleo de Estudos Afro-Brasileiros, a partir das discussões realizadas no próprio $\mathrm{Núcleo}^{2}$ e nas disciplinas de História da África I e II, ministradas pela professora Dra. Claudia Mortari. Abaixo, a tabela dos conteúdos trabalhados no curso à distância em seus respectivos módulos e capítulos:

Tabela 1: Relação da estrutura do curso com as temáticas abordadas

\begin{tabular}{|l|l|}
\hline \multicolumn{1}{|c|}{ A estrutura do curso } & \multicolumn{1}{|c|}{ Temática/Conteúdos } \\
\hline $\begin{array}{l}\text { Módulo 1 } \\
\text { “O Ensino de História da(s) África(s): }\end{array}$ & $\begin{array}{l}\text { Capítulo I. O Ensino de História da África e } \\
\text { Historiografia }\end{array}$ \\
\hline
\end{tabular}

${ }^{2} \mathrm{O}$ Núcleo de Estudos Afro-Brasileiros (NEAB/UDESC) desenvolve projetos de pesquisa e de extensão que possibilitaram a produção deste material. Dentre eles, destacamos alguns que foram fundamentais para $\mathrm{O}$ desenvolvimento dos módulos didáticos: o projeto de pesquisa intitulado "Homens e mulheres de cor e de qualidade. Um estudo acerca das identidades/identificações das populações de origem africana em Desterro/Florianópolis, 1870/1910”, coordenado pela professora Doutora Claudia Mortari; o projeto de pesquisa intitulado "Ensino de História de Áfricas em Santa Catarina: questões e perspectivas", coordenado pelo professor Doutor Paulino de Jesus Francisco Cardoso; o programa de extensão "Diversidade Étnica na Educação", coordenado pela professora Doutora Claudia Mortari; e o programa de extensão "Memorial Antonieta de Barros”, coordenado pelo professor Doutor Paulino de Jesus Francisco Cardoso. 
O ensino de história da África na formação continuada de professores: desafios e perspectivas para a educação

\begin{tabular}{|c|c|}
\hline alguns apontamentos" & $\begin{array}{l}\text { Capítulo II. Formas africanas de lidar com o passado: } \\
\text { oralidade, mitos, ritos, tradições. }\end{array}$ \\
\hline \multirow{2}{*}{$\begin{array}{l}\text { Módulo } 2 \\
\text { História da África (séculos XVI ao XIX) }\end{array}$} & Capítulo I. Algumas sociedades africanas \\
\hline & Capítulo II. A escravidão em África \\
\hline \multirow{4}{*}{$\begin{array}{l}\text { Módulo } 3 \\
\text { Experiências das populações africanas e } \\
\text { afrodescendentes na diáspora brasileira }\end{array}$} & Capítulo I. Pensando a diáspora: algumas questões. \\
\hline & $\begin{array}{l}\text { Capítulo II. Formas de viver a vida: a constituição dos } \\
\text { vínculos de parentesco. }\end{array}$ \\
\hline & Capítulo III. As Irmandades Religiosas \\
\hline & $\begin{array}{l}\text { Capítulo IV. Outras experiências no século XX: } \\
\text { pensando o Pan-africanismo, a Negritude e o } \\
\text { Movimento Negro. }\end{array}$ \\
\hline
\end{tabular}

Além do principal material pedagógico do curso (os módulos didáticos), foram disponibilizados outros materiais de suporte para a implementação de práticas de ensino, possibilitando aos professores cursistas $^{3}$ se aprofundar nas temáticas trabalhadas e terem instrumentos pedagógicos para aplicarem em sala de aula. Compõem este material complementar: textos e artigos científicos, indicações de sites e blogs, documentos históricos (iconografias, relatos de viajantes, mapas), indicação de filmes e entrevistas com especialistas na área.

Uma vez feitas as leituras de cada capítulo, os professores cursistas tinham que participar em todas as discussões dos fóruns, que se constituem em um espaço de debate em que os tutores e participantes expunham suas reflexões e considerações acerca da temática estudada. Através destes fóruns foi possível perceber e analisar se ocorreu por parte dos professores a apropriação e problematização dos conceitos, abordagens e conteúdos propostos pelo curso.

\section{A FORMAÇÃO CONTINUAdA DE PROFESSORES E O ENSINO DE HISTÓRIA E CULTURA AFRICANA E AFRO-BRASILEIRA}

A aprovação Lei Federal n. ${ }^{\circ}$ 10.639/20034 e das Diretrizes Curriculares Nacionais para a Educação das Relações Étnico-Raciais e para o Ensino de História e Cultura Afro-Brasileira e Africana (Resolução no 1, de 17 de junho de 2004) está pautada na ideia de que o conhecimento

\footnotetext{
${ }^{3}$ Optou-se em identificar os professores da educação básica participantes do curso como professores cursistas, para diferenciá-los dos professores e pesquisadores que atuaram como tutores. Estes tinham como papel instigar os cursistas a aprofundarem suas discussões bem como provocá-los com outras reflexões.

${ }^{4}$ A lei 10.639/2003 alterou a Lei das Diretrizes e Bases da Educação Nacional (nº 9394/1996), estabelecendo a obrigatoriedade do ensino de História e Cultura Afro-Brasileira. Em 2008, a mesma foi modificada pela lei 11.645/08, tornando obrigatório também o ensino da história e cultura indígena nos currículos escolares. Utilizamos como referência a lei 10.639/03 pelo reconhecimento da luta pela igualdade racial protagonizada por educadores e organizações antirracistas, principalmente o Movimento Negro.
} 
possibilita romper e contestar ideologias e preconceitos instituídos na sociedade brasileira, através de uma pedagogia antirracista. Isto porque, estudos recentes sobre desigualdade e pobreza no Brasil apontam que a negação da contribuição histórica dos africanos (e seus descendentes) pode ser considerada fator de exclusão e produção de desigualdade, conforme aponta Claudia Mortari (2015). A implementação destes dispositivos, portanto, colabora sobremaneira para o combate ao racismo e à discriminação. Além disso, representam o rompimento com o silêncio oficial sobre a questão (MORTARI, 2015).

Nesta perspectiva, é necessário o planejamento de ações que efetivem a implementação da Lei Federal 10.639/2003 e das Diretrizes nos sistemas educacionais, o que inclui também a introdução de novas abordagens e perspectivas de ensino na escola e a produção de novos conhecimentos. E o professor não deve se eximir destes debates, como se percebe na fala de uma das professoras cursistas :

Penso que discutir relações raciais no Brasil é algo que incomoda mesmo a todos, mas acredito que nós professoras e professores não podemos olhar para nossos alunos negros e brancos como vítimas desses processo[s]. Vitimiza-los não os ajuda a enxergar de modo diferenciado o processo histórico que todos nós vivenciamos. Por isso, é necessário desconstruir as chacotas, as piadas, etc. Por que são manifestações de racismo. Não podemos permitir esse tipo de situação. Uma estrategia que tenho utilizado bastante é colocar em evidencia os estudantes que percebo mais resistentes, reticentes com o debate e até mesmo mais preconceituosos. Faze-los falar, exporem seus pontos de vista e depois vou mostrando as condições de produção do pensamento apresentado por eles, as lacunas que apresentam e preconceitos que expressam ${ }^{5}$

A formação do professor, então, é fundamental para a implementação da lei, uma vez que, como afirma Mônica Lima (2009), é na sala de aula que a maioria dos jovens brasileiros entrará em contato pela primeira vez com o continente africano como um espaço de produção de saberes. Sabe-se que a educação não está presente apenas em escolas e universidades, mas estas ainda são consideradas os principais locais de formação de posturas e perspectivas. Este papel fundamental do professor como formador de agentes transformadores esteve presente nas discussões feitas pelos cursistas nos fóruns. Como no exemplo a seguir:

A História Brasileira é uma construção européia, aliás, afirmo até que seja um apêndice conforme análise proferida pelo sociólogo Emir Sader na palestra "África: um continente sem história?". Todavia, estamos numa fase de desconstrução de paradigmas que se, por um lado, é bom devido a desmi[s]tificação ou a aproximação de uma História mais "imparcial", por outro, no[s] coloca como eixo fundamental nesse processo devido nosso papel social de formadores de opinião enquanto professores. Não que a igreja, os partidos, etc., não tenham essa responsabilidade, mas o eixo formativo, reparador, e disseminador dessa nova visão antropológica e histórica de análise

\footnotetext{
${ }^{5}$ Comentário realizado por um professor cursista no Fórum 1. Optou-se em não divulgar os nomes dos professores cursistas com o objetivo de preservar a identidade dos mesmos.
} 
da humanidade cabe primeiramente nós, aos cientistas políticos, e sociais e todos que de algum modo queiram se agregar. $[\mathrm{sic}]^{6}$

No entanto, várias dificuldades e obstáculos estão presentes neste caminho. Inicialmente deve-se considerar que o currículo multicultural para o ensino ainda se configura como uma proposta pedagógica nova, visto que não cabe no funcionamento tradicional das instituições de ensino $^{7}$. Ainda, segundo Lima (2009), grande parte da geração de professores que atua no ensino básico e procura cursos de formação continuada de História da África, afirmam nunca ter tido contato com a temática na graduação, portanto, ainda não se consideram preparados para ensinála na sala de aula. Como consequência disto, afirmam que não encontram bibliografias de boa qualidade nem material didático para trabalhar com os alunos:

Acredito que durante todo esse tempo que estivemos estudando como alunos, em todos os níveis, só tínhamos a visão eurocêntrica, até mesmo porque não havia uma outra visão. A partir dos anos 1970, começamos a ter um novo material, com ponto de vista dos africanos. Até hoje, a bibliografia é pequena, mas crescendo de uma maneira que em breve teremos que pensar onde, em que nível de ensino terá que se colocar para recuperarmos o tempo que foi perdido. A estrutura dos currículos das disciplinas de história, geografia, literatura, religião e artes (gráfica e musical) deverão ser revistos e selecionados em uma nova estrutura. Bem-vindo os novos conhecimentos e seus novos pontos de vistas, que ajudarão a entendermos a nossa história. ${ }^{8}$

Tal citação evidencia que para além da necessidade da produção de material didático para o professor, precisamos repensar as estruturas dos currículos das disciplinas escolares e não apenas a inclusão destes conteúdos. Por outro lado, é preciso assinalar que a Legislação indica que as disciplinas de História, Geografia e Artes devem, preferencialmente, trabalhar com a temática, mas não significa que as outras não possam incorporá-la.

É óbvio que o acesso não orientado aos estudos publicados sobre a História da África e a insegurança para montar suas aulas se configuram como argumentos de que o professor não pode ensinar o que não aprendeu (OLIVA, 2006). Contudo, isto não justifica um absoluto imobilismo dos professores em tratarem da temática. Ao lançar este desafio para os professores, entendemos que, através dos materiais disponíveis, mesmo eles tratando da África a partir de valores eurocêntricos, é possível problematizá-los e discutir com os alunos o porquê deste

\footnotetext{
${ }^{6}$ Comentário realizado por um professor cursista no Fórum 1.

7 Entendemos por currículo multicultural nas escolas aquele que reconhece e implementa em suas ações educativas estratégias e atividades que abordem a sociedade brasileira em sua pluralidade: valorizando indígenas, africanos e afrodescendentes e descendentes de europeus. A partir desta perspectiva, a educação escolar visa a construção de uma sociedade democrática cultural. Para maior aprofundamento, ver: TORRES, Carlos Alberto. Em busca de uma teoria da cidadania multicultural democrática. In: Democracia, Educação e Multiculturalismo: dilemas da cidadania em um mundo globalizado. Petrópolis: Editora Vozes, 2001. 247-289.

${ }^{8}$ Comentário realizado por um professor cursista no Fórum 1.
} 
conteúdo ser mostrado desta maneira e apresentar outras perspectivas possíveis. Tal concepção foi abordada por alguns professores cursistas que abraçaram o desafio:

...mesmo com a implementação da Lei os livros didáticos e materiais de apoio [...] ainda não mudaram a perspectiva eurocêntrica do conteúdo. [...] da mesma forma, o livro didático é muito tímido em relação às Áfricas, ainda propondo que as histórias se iniciam com a exploração do tráfico de escravos.

Desta forma, fazer uma leitura geral do livro didático e dos Cadernos do Aluno orientando os alunos a se posicionarem em uma perspectiva africana já nos permite realizar a critica do tipo de ensino que se propõe na escola pública. Esta identificação é uma atividade a ser realizada em grupos e podemos, ainda, preparar pesquisas que relacionem no tempo o que ocorria nas Áfricas para ser apresentado aos demais grupos da sala. ${ }^{9}$

No curso "Introdução aos Estudos Africanos e da Diáspora", dentre os professores que o concluíram, a maioria havia se graduado entre os anos de 2006 e 2012, conforme demonstra o gráfico a seguir ${ }^{10}$. A motivação para realizá-lo, segundo estes, foi a procura por capacitação na temática para poder se adequar e atuar no ensino, implementando a Lei Federal 10.639/03 e, mais especificamente, capacitar-se para lidar com questões relacionadas ao desconhecimento da temática e ao racismo profissionalmente no dia-a-dia.

Gráfico 1: Ano de formação dos cursistas ${ }^{11}$

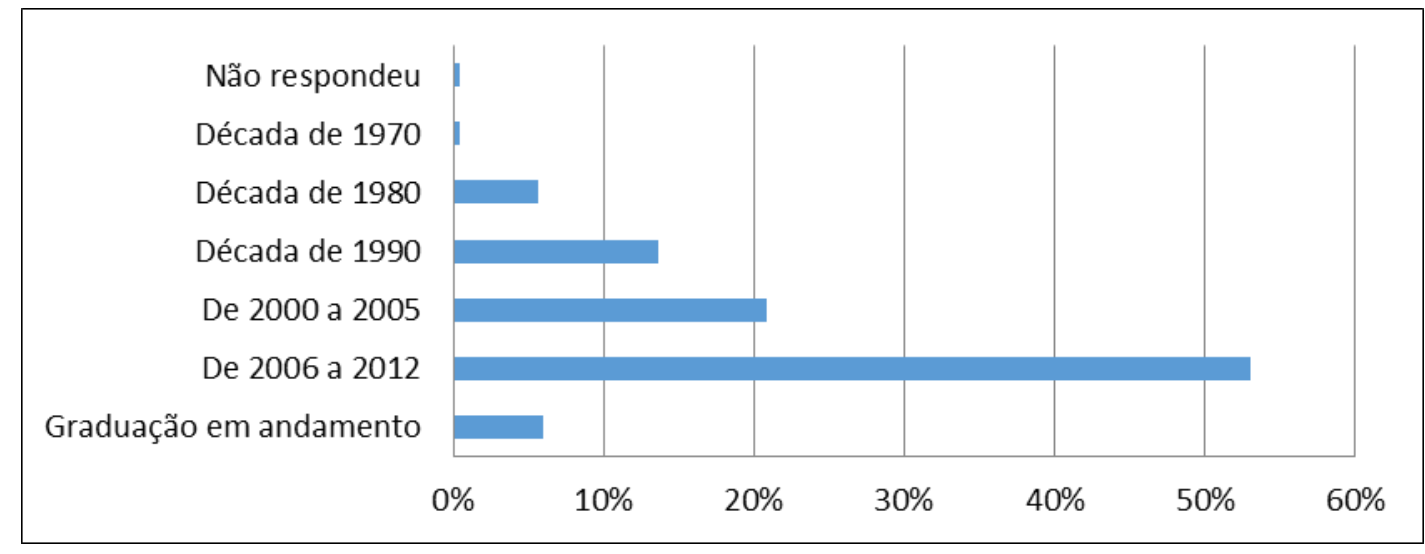

Percebe-se que, mesmo tendo se graduado após 2003, ano da sanção da Lei Federal 10.639, muitos destes profissionais não tiveram em sua formação o acesso a conteúdos para o ensino de história e cultura africana e afro-brasileira e buscaram um curso de formação continuada com o intuito de se aprofundar nas temáticas.

\footnotetext{
${ }^{9}$ Comentário realizado por um professor cursista no Fórum 1.

${ }^{10}$ Foram oferecidas 500 vagas nesta edição do curso. Todas foram preenchidas e ainda tivemos uma lista de espera com 200 interessados em realizá-lo. Encerramos o curso com 35\% de professores que receberam certificação, ou seja, 164 professores que participaram ativamente durante todo o curso, obtendo $100 \%$ de aproveitamento.

${ }^{11}$ Dados obtidos através do questionário de inscrição do curso.
} 
Foram oferecidas 500 vagas nesta edição do curso, sendo que todas foram preenchidas. A procura se deu por todas as regiões do país, inclusive tivemos uma inscrição de um professor que atuava na Alemanha. O gráfico a seguir evidencia que, embora contássemos com professores cursistas de todo o país, a região Nordeste teve mais inscrições:

Gráfico 2: Porcentagem de cursistas por região ${ }^{12}$

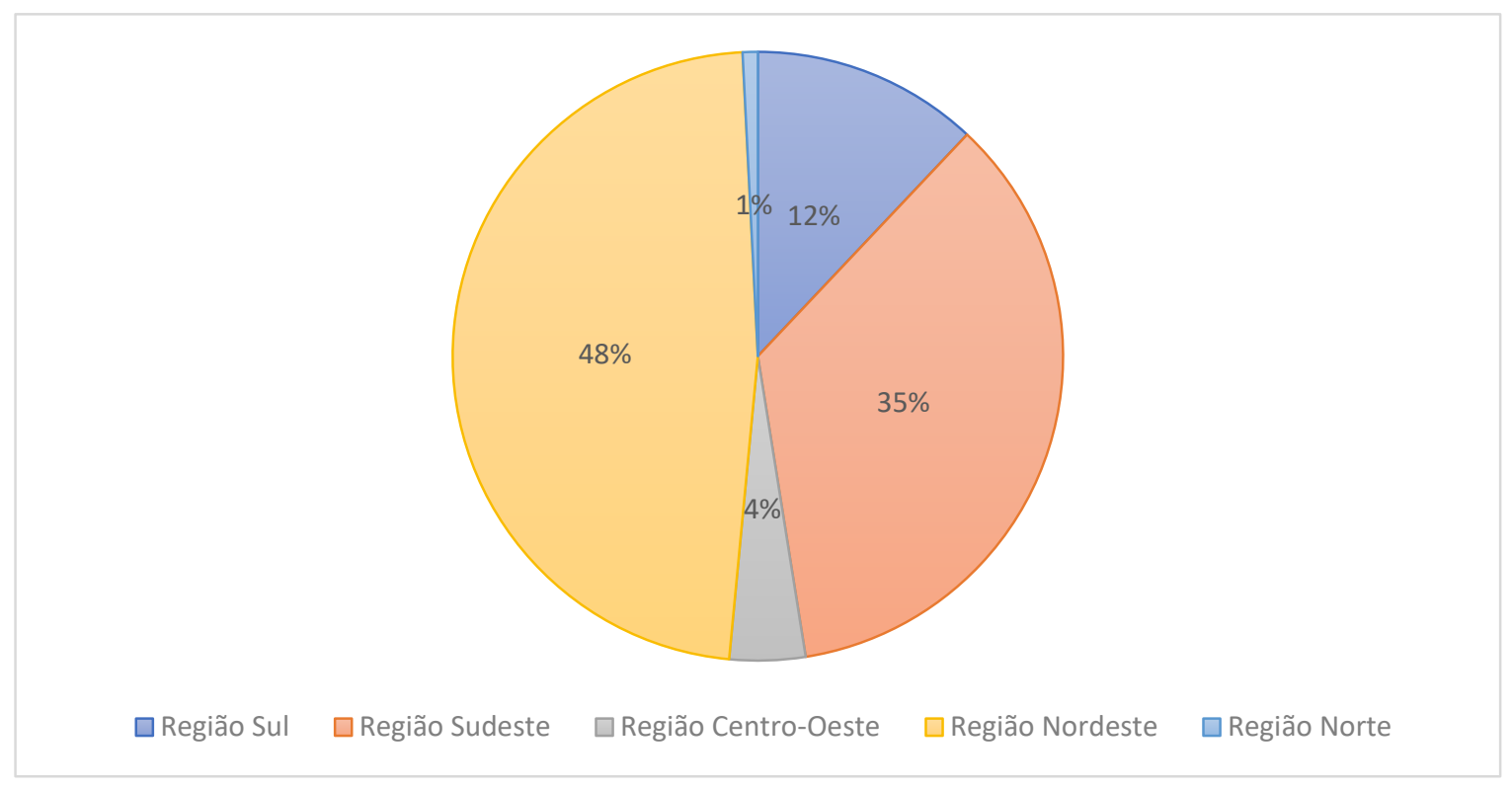

Outro fator importante do perfil dos professores cursistas é que a grande maioria deles atua na área de História, ou seja, tem graduação na disciplina. No entanto, dos cursistas finalistas, somente dezessete se enquadraram neste perfil, isto é, 10\% do total. Os outros 90\% atuavam em diversas áreas, desde a Biologia ao Teatro. A existência de um maior número de profissionais de outras áreas do conhecimento que procuraram fazer o curso nos indica, de uma maneira positiva, a formação de uma postura pedagógica que compreende a necessidade de implementação dos conteúdos para além daquelas disciplinas assinaladas na legislação.

Destes dezessete professores, onze já haviam realizado cursos na temática e onze haviam cursado alguma disciplina com a temática de História da África na graduação. Ainda, segundo eles, a abordagem dada à história das populações africanas e afrodescendentes foi a de valorização e discussão crítica destas populações e sua contribuição na cultura e história. Contudo, em todos os casos, esta perspectiva foi abordada somente na disciplina específica e durante um semestre. Alguns ainda apontaram que além de não contarem com uma disciplina específica de História da África, a abordagem em relação ao tema foi feita sob a ótica da

12 Dados obtidos através do questionário de inscrição do curso. 
O ensino de história da África na formação continuada de professores: desafios e perspectivas para a educação

escravidão nas disciplinas de História do Brasil. A motivação para participar do curso foi, portanto, o aprofundamento dos estudos na temática, mas principalmente o entendimento de uma abordagem que coloca as populações africanas e da diáspora como partícipes construtores da História e não apenas como objetos.

\section{AS DISCUSSÕES FEITAS NOS FÓRUNS: A CONSTRUÇÃO DE UMA NOVA PERSPECTIVA ACERCA DAS ÁFRICAS}

A proposta do curso parte da ideia central de que para mudarmos nossas concepções hegemônicas e enfrentarmos as desigualdades e preconceitos incrustados na sociedade, é necessário conhecer, discutir, problematizar e refletir sobre a história das Áfricas e de suas populações ${ }^{13}$. A intenção, neste sentido, é de construir uma nova perspectiva sensível às experiências e histórias dos sujeitos, destituída de ideias preconcebidas e de estereótipos. Lança-se o desafio de pensar e refletir sobre as diversidades.

Assim, uma das questões colocadas como reflexão para os cursistas foi os sentidos e os processos de construção do conhecimento histórico. Para tanto, seguindo a linha de pensamento de Leila Hernandez (2005), é preciso problematizar a ideia de uma "invenção da África". Tal invenção está relacionada à uma construção do conhecimento que advém do racionalismo, que surge no século XVI e é consolidado entre a segunda metade do século XVIII e a primeira metade do XIX. Este conhecimento fundamentou valores políticos, éticos e morais ditos modernos, que dominaram o pensamento ocidental. Aqueles que não os possuíam, ou que os ocidentais acreditavam que não possuíam, são menos capazes.

Assim, a África e os africanos foram julgados sob os pressupostos dos europeus, sem qualquer relativismo e sem analisar a sua cultura: "aproximando-se por analogia o desconhecido ao conhecido considera-se que a África não tem povo, não tem nação e nem Estado; não tem passado, logo, não tem História” (HERNANDEZ, 2005, p. 18). O pensamento sobre a historicidade africana só vai mudar em meados do século XX, quando esta vai ser considerada como um problema histórico e político em que se busca explicar a África pela sua pluralidade. O primeiro fórum de discussão tinha como propósito a discussão elencada anteriormente. Assim, propunha aos professores que elaborassem um trabalho que pudesse ser desenvolvido em sala de aula com base no que foi discutido nos conteúdos estudados, instigando a construção de um novo olhar, destituído de ideias preconcebidas e de estereótipos.

13 Trabalhamos com a ideia de Áfricas, no plural, por compreendermos o continente africano e suas populações caracterizados pela diversidade. Embora existam visões de mundo e saberes comuns entre as diversas sociedades africanas, várias outras questões nos permitem enxergá-las marcadas pela heterogeneidade. 
Neste sentido, em todas as postagens, os professores cursistas salientaram a importância de inserir nas suas aulas as histórias e culturas africanas a partir de uma abordagem voltada para os valores do continente africano, problematizando a imagem estereotipada da África presente nos livros didáticos e demais meios de comunicação. Como se depreende dos comentários a seguir:

Inicialmente solicitaria que elaborassem uma lista ou desenhos com informações que possuem sobre o continente africano. Essa atividade poderia ser retomada ao final do ano para percebermos se as impressões iniciais se alteraram, se o olhar para o continente africano é o mesmo ou não. Partindo disso abre-se o leque para pensar que essa imagem popularmente conhecida da África é uma imagem que o mundo ocidental criou de um continente isolado, exótico, primitivo, selvagem, atrasado que se integra á História apenas com a chegada dos europeus. ${ }^{14}$ [sic]

Em uma de minhas experiências em sala de aula, pedi para meus alunos escreverem quais são as primeiras ideias que eles tinham sobre a África, e a grande maioria me respondeu: fome, miséria, doenças e escravidão. Isto posto, procurei mostrá-los a diversidade cultura presentes nas Áfricas e a relação com a história brasileira. Para isto, utilizei alguns videos musicais de ritmos como o reggae, rap, blues e samba, intercalando com a forte presença que a música da diáspora negra tem em nossa cultura. ${ }^{15}[\mathrm{sic}]$

A estratégia destes professores de partir das impressões próprias de seus alunos foi muito válida, uma vez que isto aproxima o conteúdo escolar do seu cotidiano. Iniciar os estudos sobre culturas e histórias africanas partindo do presente é um exercício eficaz, uma vez que considera a consciência histórica dos alunos e a complexifica ${ }^{16}$. Dificilmente as imagens de miséria, fome e mundo selvagem que os alunos têm da África desaparecerão para sempre. Contudo, é importante ensiná-los que as Áfricas não são somente isto. Não é desconsiderar os problemas sociais, econômicos e políticos presentes no continente africano contemporâneo, mas compreender que estes são apenas uma faceta do território, assim como o são na Europa ou nas Américas. Nesta perspectiva, um professor cursista propôs trabalhar a temática não isolada em si mesma, mas sempre concomitante à história de outras populações, principalmente fazendo conexões com a História do Brasil, como se evidencia no comentário a seguir:

\footnotetext{
${ }^{14}$ Comentário realizado por um professor cursista no Fórum 2.

${ }^{15}$ Comentário realizado por um professor cursista no Fórum 2.

${ }^{16}$ Compreendemos consciência histórica como uma forma de se orientar no espaço temporal; a maneira como as pessoas experienciam, interpretam e se ordenam no tempo - referenciado por passado, presente e futuro. Assim, o papel do professor é desenvolver o pensamento histórico nos alunos, isto é, capacitá-los com ferramentas de investigação próprias da ciência historiográfica para trabalharem a partir da análise de documentos e/ou acontecimentos históricos. Sobre esta questão ver: RÜSEN, Jörn. Didática da História: passado, presente e perspectivas a partir do caso alemão. Práxis Educativa, Ponta Grossa, vol. 1, n 2, p. 07-16, jul.-dez. 2006; e SILVA, Cristiani Bereta da. O ensino de História - algumas reflexões do Reino Unido: entrevista com Peter J. Lee. Revista Tempo e Argumento, Florianópolis, v. 4, n. 2, pp. 216 - 250, jul/dez. 2012.
} 
No desenvolvimento das minhas aulas de história procuro sempre desenvolver relações entre diferentes fenômenos históricos e povos, como forma dos discentes perceberem como as "coisas" estão inter-conectadas, facilitando também o aprendizado deles em relação a tantos fenômenos históricos trabalhados na disciplina.

Portanto, o ensino de história das Áfricas com relação aos outros povos se torna profícuo na medida em que o aluno consegue estabelecer o novo conteúdo a ser aprendido com o anterior. No entanto, conforme expresso no capítulo 1 deste curso, o ensino de História da África não pode somente privilegiar este aspecto, isto é, os fatores exógenos, desse modo, desenvolvo com os meus alunos uma análise detalhada da particularidade dos povos africanos estudados naquele contexto histórico. Desse modo o contexto histórico estudado seria porta de entrada para o estudo focalizado das realidades dos povos africanos. ${ }^{17}$

O professor cursista propôs, portanto, perceber a África a partir dos processos endógenos e exógenos que fazem parte da sua história. Até mesmo porque, Serrano e Waldman (2007) afirmam que o continente nunca esteve isolado, ao contrário, é e foi marcado pelo contato com outras populações, que propiciou um intercâmbio cultural e étnico, além de trocas comerciais; e também por deslocamentos e migrações, internas e externas, dos povos africanos. Tal proposição indica um caminho interessante inclusive para estudar a temática no campo da geografia. Aliás, tal ideia foi apontada por um professor, conforme o comentário a seguir.

É preciso situar o aluno quanto à localização do continente africano no mapa mundi e pedir que em grupo, escolham um país do continente que desejam conhecer. Nesse momento talvez seja necessário pedir que coloquem no papel suas impressões sobre o país escolhido como por exemplo a economia, a religião, costumes e outros aspectos que o professor ache importante. Peça que troquem suas impressões com os colegas do grupo e observem o quanto elas coincidem e quais as diferenças entre as mesmas. Para casa, peça que o aluno pesquise sobre o país escolhido pelo grupo e que montem um vídeo com imagens e informações colhidas na pesquisa marque o dia das apresentações e em seguida discuta com a turma sobre a relação entre o que eles pensavam sobre o país escolhido e o que encontraram na pesquisa. Peça que concluam o trabalho fazendo uma reflexão sobre o que aprenderam.

Os alunos terão uma visão dos países do continente africano bem diferente daquela retratada na mídia e no livro didático. ${ }^{18}$

Este comentário também assinala para outro aspecto importante: o estudo do espaço geográfico possibilita apreender as diversidades presentes no território. Portanto, a abordagem histórica da África deve ser feita analisando-se sua extensão territorial, aspectos geográficos distintos, a presença de vários povos com diferentes modos de organização socioeconômica e diferente cultura, a mais longa ocupação humana que se conhece e o contexto das migrações que

${ }^{17}$ Comentário realizado por um professor cursista no Fórum 2.
${ }^{18}$ Comentário realizado por um professor cursista no Fórum 2. 
nela ocorreram. Ou seja, não se pode estudar a África sem se ter conhecimento sobre as suas peculiaridades continentais.

Aliado ao conhecimento geográfico é fundamental pensarmos nos sujeitos que compõem sua paisagem. Neste sentido, o ser africano apresenta características próprias e diversas. O pensamento histórico destas populações, segundo Hampaté Bâ (1982), é caracterizado por dois aspectos fundamentais: sua atemporalidade e sua dimensão essencialmente social. Para a sua construção é necessário discutir os conceitos de tradição e ancestralidade africanas. O segundo fórum, então, teve como problemática a importância da oralidade, da tradição e da memória para as populações africanas. Para elas, questões como a palavra, o mito, o tempo, a memória, servem de base para o seu ser, estar e explicar o mundo. A partir destas considerações e do material de base, os cursistas deveriam apontar os princípios que norteiam a tradição oral. A seguir, destacamos uma das discussões apontadas pelos cursistas:

Podemos verificar a presença de alguns princípios da tradição oral africana: o princípio da sacralidade da fala e como tal, impassível de equívocos; seguido do princípio da relação entre a mente e a palavra, segundo o qual, aquele que pensa diferente do que diz, está realizando um desequilibrio em seu interior e ao seu redor.

As palavras ditas corretamente em consonância com a mente, entoadas e cadência das de um determinado modo nos rituais africanos, são determina[n]tes para o sucesso destes.

Já na tradição oral, as palavras e o ato da fala possui a importância de perpetuar a história comum das sociedades africanas. Através da transmissão oral, os saberes das gerações preteritas seriam preservados, assim como as identidades das instituições sociais. ${ }^{19}$

A oralidade foi o ponto mais marcante nas respostas dos professores: a palavra falada foi colocada como um valor moral fundamental além de um caráter sagrado vinculado à sua origem divina. A tradição africana é essencialmente oral e a ancestralidade está intimamente ligada à memória, uma vez que há uma tentativa constante de invocar o passado e o tempo, pois "a causalidade atua em todas as direções: o passado sobre o presente e o presente sobre o futuro". (BOUBOU; KI-ZERBO, 1982, p. 62) ${ }^{20}$. Cada população possui um mito fundador e este, por

\footnotetext{
${ }^{19}$ Comentário realizado por um professor cursista no Fórum 2.

${ }^{20}$ Para as sociedades africanas a oralidade é um elemento importante que serve de base para o seu ser, estar e explicar o mundo. A palavra falada possui um valor moral fundamental além de um caráter sagrado vinculado à sua origem divina e é considerada a materialização da vibração das forças. A oralidade é, neste sentido, a maneira pela qual se transmite o conhecimento, a história e a memória. Para maior aprofundamento sobre a oralidade nas sociedades africanas ver: KI-ZERBO, J., BOUBOU, Hama. Lugar da história na sociedade africana. In: KI-ZERBO (coord.). História Geral da África I. Metodologia e pré-história da África. São Paulo: Ática; Paris: UNESCO, 1982, p. 61-71; HAMPATÉ BÂ, A. A tradição viva. In: KI-ZERBO (coord.). História
} Geral da África I. Metodologia e pré-história da África. São Paulo: Ática; Paris: UNESCO, 1982, p.181-218 
sua vez, governa e justifica a história. Ao tecerem considerações sobre a problemática do segundo fórum, os cursistas centraram suas respostas na concepção da palavra. ${ }^{21}$

Neste sentido, uma vez que a história, os mitos, e a oralidade estão conectados na cosmogonia africana, o segundo elemento corrente nas discussões dos cursistas foi refletir sobre as formas de lidar com o passado e com a história através da palavra. O comentário a seguir nos apresenta alguns indícios importantes acerca da apropriação destas formas de se ver o mundo pelo professor. Além disto, acrescenta um debate interessante no sentido de se trabalhar a memória como uma fonte histórica:

A concepção que havia anteriormente, mas precisamente com os historiadores europeus do século XIX era de que a história devia ser fundamentada em documentos oficiais, tanto que a divisão (que inclusive ainda é adotada atualmente) entre Pré-História e História tem esse pressuposto. Porém, com o desenvolvimento da Ciência da História e principalmente com a PósModernidade, a contribuição da Antropologia e das Ciências Sociais trouxe uma nova perspectiva de documento histórico. Abriu-se um leque de possibilidades para o estudo da história que nos mostrou novas formas de entender comunidades e sociedades com roupagens diferentes, tentando assim, romper com o eurocentrismo. A tradição oral é considerada hoje uma fonte histórica bastante rica e passível de estudos sobre os povos com heranças culturais muito antigas. No caso da África, é possível com isso valorizar, através do reconhecimento da oralidade como fonte histórica, a perpetuação de tradições e costumes através da oralidade e da importância dela para uma comunidade. ${ }^{22}$

Percebemos, ainda, no comentário do professor o conhecimento adquirido através das discussões propostas pelo material didático do curso: tenta-se entender a África pelos seus próprios pressupostos, ou seja, vista do interior, considerando-se toda a sua pluralidade e diversidade, fundamentais para compreender o processo histórico protagonizado pelos africanos e não regrada por padrões de valores estrangeiros ${ }^{23}$. As narrativas escritas produzidas pelo olhar de fora da África são essenciais porque nos fornecem uma estrutura cronológica da sua história, de sua história econômica (rotas comerciais, principais mercados, recursos naturais, agricultura, entre outros); e observações, ainda que do ponto de vista europeu, dos costumes e cotidiano africanos (vestimentas, comportamentos e até estratégias de guerra).

Neste contexto, podemos utilizar os relatos de viajantes, de missionários, de cônsules, colonizadores e aventureiros como fonte para se entender os povos africanos. Por outro lado,

\footnotetext{
21 O papel dos tutores do curso, neste sentido, foi fundamental, pois instigaram os cursistas a fazer relações com a Diáspora, principalmente com o Brasil, e sobre a relação dos mitos e ancestralidade, os mesmos retomaram os textos bases e fizeram comentários a respeito.

22 Comentário realizado por um professor cursista no Fórum 2.

$23 \mathrm{O}$ material didático elaborado para o curso foi compilado e publicado em formato de livro: MORTARI, Claudia (org). Introdução aos Estudos Africanos e da Diáspora. Florianópolis: DIOESC: UDESC, 2015. O livro foi impresso e distribuído para diversas universidades brasileiras.
} 
O ensino de história da África na formação continuada de professores: desafios e perspectivas para a educação

para compreendermos as Áfricas, é necessário considerar também as fontes orais e os testemunhos escritos dos próprios africanos, pois assim, mais a história da África se diversifica e se constrói de diferentes formas.

\section{CONSIDERAÇÕES FINAIS}

Considerando-se estas reflexões acerca do conhecimento histórico sobre África e da sua invenção, devemos compreender que tais categorias, como o conceito racial e a vertente do racionalismo, construíram, a partir de preconceitos e pré-noções, uma concepção ocidental de África. Esta construção histórica é feita em cima do completo desconhecimento da diversidade das populações africanas, sendo que estas foram classificadas de forma homogênea. Portanto, para se conhecer o continente africano é necessário estudá-lo e analisá-lo a partir de todas as suas singularidades e pluralidades. Somente assim os estereótipos produzidos acerca deste continente poderão ser desconstruídos.

A partir do curso Introdução aos Estudos Africanos e da Diáspora vislumbramos algumas perspectivas e desafios para o ensino de história da África. Através das reflexões dos professores, percebemos que é possível transformar as abordagens sobre o continente africano a partir de uma percepção mais sensível acerca dele e dos sujeitos históricos que nele vivem e viveram, compreendendo suas próprias especificidades, cosmogonias e modos de viver. Mesmo que os materiais didáticos disponíveis apresentem imagens estereotipadas, é possível problematizá-las historicamente. O curso foi o ponto de partida para que professores participantes se capacitassem para trabalhar a temática com os seus alunos. Contudo, será na sala de aula que buscaremos formar uma sociedade mais igualitária, na qual a África, os africanos e seus descendentes serão vistos menos rotulados por estigmas e preconceitos.

\section{REFERÊNCIAS}

APPIAH, Kwame Anthony. Ilusões de raça. In: Na Casa De Meu Pai. A África na Filosofia da Cultura. Rio de Janeiro: Contraponto, 1997, pp. 53-76.

BRASIL; MINISTÉRIO DA EDUCAÇÃO; SECRETARIA ESPECIAL DE POLÍTICAS DE PROMOÇÃO DA IGUALDADE RACIAL. Diretrizes Curriculares Nacionais para a Educação das Relações Étnico-Raciais e para o Ensino de História e Cultura AfroBrasileira e Africana. Brasília: MEC, 2004. 
O ensino de história da África na formação continuada de professores: desafios e perspectivas para a educação

KI-ZERBO, J.; BOUBOU, Hama. Lugar da história na sociedade africana. In: KI-ZERBO (coord.). História Geral da África I. Metodologia e pré-história da África. São Paulo: Ática; Paris: UNESCO, 1982, pp. 61-71.

HAMPATÉ BÂ, A. A tradição viva. In: KI-ZERBO (coord.). História Geral da África I. Metodologia e pré-história da África. São Paulo: Ática; Paris: UNESCO, 1982, pp.181-218.

HERNANDEZ, Leila Leite. A África na sala de aula: visita a história contemporânea. Belo Horizonte: Selo Negro, 2005.

LIMA, Mônica. Aprendendo e ensinando história da África no Brasil: desafios e possibilidades. In: ROCHA, Helenice Aparrecida; MAGALHÃES, Marcelo de Souza; GONTIJO, Rebeca (Orgs.). A escrita da história escolar: memória e historiografia. Rio de Janeiro: Editora FGV, 2009, p. $149-164$.

MORTARI, Claudia (Org.). Introdução aos Estudos Africanos e da Diáspora. Florianópolis: DIOESC: UDESC, 2015.

OLIVA, Anderson Ribeiro. A história africana nos cursos de formação de professores. Panorama, perspectivas e experiências. Estudos Afro-Asiáticos. Ano 28, nos 1/2/3, Jan-Dez 2006, p. 187-220.

SERRANO, Carlos; WALDMAN, Maurício. Memória D’África. A temática africana na sala de aula. São Paulo: Cortez, 2007.

Recebido em: 31/05/2017

Aceito em: 06/12/2018 